They believe that their results indicate that by such forces the alcoholic has had developed strong desires to be dependent, but these are incompatible with the self-image in the stereotype of the American male-independent, courageous, dependable and resolute. Drinking satisfies this by being a 'manly' pursuit, which yet satisfied dependency desires. (I found this less cogently argued than the rest of the book.)

They note differences between the personality of the pre-alcoholic and that of the developed alcoholic; and between factors that precede criminality in one, and alcoholism in another.

It would perhaps be dangerous to generalize from this investigation about the genesis of alcoholism generally-there are some apparent differences between the alcoholics that the McCords describe and those with whom I am familiar. Nevertheless it gives what appears to be valid and reliable information on an area in which hitherto we have had little but speculation.

W. MCAdam

\section{THE BRITISH NATIONAL HEALTH SERVICE}

The Genesis of the British National Health Service By John Jewkes and Sylvia Jewkes. Pp. xi+67. (Oxford: Basil Blackwell, 1961.) 6s. 6d. net.

NHE human and financial implications of Britain's
National Health Service are so tremendous that
the significance of a survey by Prof. and Mrs. Jewkes
cannot be overrated. They question the assumptions
on which the National Health Service was established,
challenge the validity of comparisons between
Britain's centrally directed system and those of
countries where the health services owe less to central
direction and more to local enterprise, and have con-
siderable reservations about whether or not the Health
Service is as effective as its protagonists would
proclaim.

In their essay, the authors make a critical examination of the belief that, before the War, the British medical system was seriously defective and that nothing short of a centrally controlled free system could provide appropriate remedies; further inquiries are to be made into the economic and social consequences of the National Health Service. As a basis for their inquiry, the Jewkes's have investigated the numbers and distribution patterns of doctors, dentists and nurses, the numbers of general practitioners in relation to the number of consultants, comparative mortality statistics and the way in which a health service might have developed if there had been no nationalized direction and control.

Their findings are disturbing. Although the statistics are not always revealing, it would appear that, even if the number of doctors has continued to increase under the National Health Service, the rate of increase has been no greater than that which obtained during 1921-39. The same can be said of nurses and dentists, and although, apart from our lesser number of dentists, British medical services compared favourably with those of the United States in 1939, the average American to-day is much better served; the gap between us continues to widen.

With the introduction of the National Health Service it was hoped that the distribution of doctors throughout Britain would become more even.
Between 1911 and 1951 the geographical pattern remained largely unchanged and, although there was a slight gain in the number of doctors in more unpopular areas during 1951-59, the ratio still varies widely between north and south, spas and areas of heavy industry. Specialist services have improved under the National Health Service, treatment by medical consultants being now much more widely available. Nevertheless, the percentage of consultants to be found in the more attractive southern parts of the country has varied little between 1938 and 1957. Prof. and Mrs. Jewkes also indicate that the increase in the number of consultants owes much to the up-grading of men who, before the introduction of the National Health Service, were called general practitioners and whose titles alone have changed.

A frequent complaint before the Second World War was that too many doctors carried too many patients on their panels. Some improvements have taken place, but, since 1954 , the position has deteriorated. Between 1952 and 1959, for example, the average number of patients per principal in underdoctored areas fell only from 2,851 to 2,745 . The charge, too, that older people have received far less medical attention since the introduction of the Service is also refuted by the figures.

Two other points emerge from the survey. One is that, since the inception of the National Health Service, mortality-rates in England and Wales have not fallen more rapidly than in other Western countries. The second is concerned with the administrative pattern of medical services and suggests that "the more sweeping criticisms of the pre-war organization of British medical services are not to be trusted and that the view that the pre-war weaknesses could summarily be swept away by a centralized organization was over-sanguine".

The findings of this inquiry raise so many issues of national importance that many people will wish to see the promised surveys into the social and economic consequences of the National Health Service. Others will see that this inquiry is important not only for its own sake but also as an exercise in social science. In many parts of this essay, Prof. and Mrs. Jewkes take exception to statements made by Prof. R. M. Titmuss and others which were adduced to support the principle of a centrally organized health service. In so doing they themselves, however unintentionally, have raised the question of whether social scientists should begin with a view and look for information to support it, or whether more profitable diseussion might ensue if the inductive method of physical science were applied more faithfully. Is this one of the reasons why so much of social science is still looking for its basic concepts? T. H. HAwKIns

\section{A NEW MEDICAL DICTIONARY}

\section{The British Medical Dictionary}

Edited by Sir Arthur Salusbury MacNalty. Pp. xix + 1680. (London and New York: The Caxton Publishing Co., Ltd., 1961.) $210 s$.

THE appearance of this truly monumental work will be received with delight by everyone who has, systematically or occasionally, the need to consult medical journals. Coinage of new words and changed meanings for old ones have led to the emergence of an English medical vocabulary which has become almost the equivalent of a foreign 